\title{
Constructing Race and Ethnicity: "It Has to Do with Where You Are"
}

\author{
Nikita Carney ${ }^{1}$ (D)
}

Accepted: 17 May 2021 / Published online: 1 June 2021

(c) The Author(s) 2021

\begin{abstract}
Drawing from the lived experiences of Haitian women in Boston and Montreal, this study illustrates how ethnography can augment understandings of race and place in demography by complementing quantitative analyses, showing how race is constructed across place through daily micro-interactions. Building on the work of demographers who examine how race shifts over time and place, this article challenges the practice of engaging with race as a fixed or static category to consider how race is constructed across place, highlighting the nuances of race that are sometimes lost in quantitative studies. The multi-sited ethnographic methodology employed in this study is uniquely suited to uncovering the specificities of race and place. The findings reveal that Haitian women experience race differently in Montreal and in Boston, based largely on the historical context of each place. Haitians in Boston experienced intraracial tensions with African Americans, particularly during the 1960s and 1970s, that shaped their experiences of race and place, while Haitians in Montreal at the same time experienced Blackness that was closely tied with xenophobia in the French Canadian context. The Haitian women in this study experienced race, place, gender, ethnicity, and class simultaneously, necessitating an intersectional approach to understanding the effects of race in and on their daily lives.
\end{abstract}

Keywords Ethnography $\cdot$ Qualitative methods · Race $\cdot$ Place $\cdot$ Intersectionality

\section{Introduction}

Race was-and still is-considered by many to be a static concept. Quantitative scholars rely on that understanding of race — at least implicitly — when using cross-sectional, point-in time measures of race, but scholars have demonstrated that dimensions of race vary over time (e.g. Liebler \& Hou, 2020; Liebler et al. 2017),

Nikita Carney

ncarney@1su.edu

1 Department of Sociology and African \& African American Studies, Louisiana State University, 10B Stubbs Hall, Baton Rouge, LA 70803, USA 
place (e.g., Roth, 2012), and even different interactions (e.g., Saperstein \& Penner, 2012). Race is complex; understanding that complexity better equips us to recognize the ways that race operates in daily life and subsequently affects a range of demographic outcomes (e.g., marriage, employment, income, homeownership, health, mortality). In this research, I ask how it is that people-and Haitian women in particular-become racialized through daily interactions. Moreover, through a comparison of these experiences in Boston and Montreal, I demonstrate how the context of each place shapes the ways in which race and ethnicity are constructed.

Ethnographic data complement quantitative and primarily survey data analyses that have dominated demographic research by revealing the nuances of where and how categories of race are negotiated. Based on ethnographic fieldwork in Boston and Montreal, this study highlights how context shapes the manifestation of race and ethnicity in the lives of Haitian women through their paid labor. While most Haitians are always clearly categorized as Black, the ways in which the category of Black is shaped, understood, and experienced looks different depending on location and time. In addition to revealing more of the specificities about the ways in which race and ethnicity are constructed, this research unpacks the relationship between place and the social construction of race.

Ethnographic data on race and place can complement some of the large-scale quantitative research done in this field. This study aims to follow the experiences of Haitian women migrants across place to reveal specificities about the ways in which race and ethnicity are constructed. Looking at multiple, separate geographic contexts allows for a more nuanced analysis of the construction of race than a single-sited study might have allowed (Carney, 2017; Falzon, 2016; Hannerz, 2003; Marcus, 1995). Though there are similarities across place, race is constructed differently in Boston and Montreal. This has important implications for how we understand race broadly speaking as a social concept. The purpose of this study is to offer insight to inform how spatial demographers understand categories of race and place. Engaging with this ethnographic study of how race and ethnicity are formed and negotiated can give spatial demographers additional depth in conceptualizing the categories of race and ethnicity in their work rather than using race and place as taken-for-granted categories. Hopefully these insights will further encourage the types of innovative strategies some spatial demographers have begun to engage, allowing for race's relationship to vary across space (e.g. Curtis \& O’Connell, 2017; Picket, Saperstein, and Penner 2019). In other cases where it might not be possible to adjust the research design to account for variations in race across space, scholars may choose to refer to studies such as this one to inform the interpretation of data related to race and space; engaging with such a study offers the opportunity to look critically at the category of race and consider what local-level phenomena the macro-level data may be obscuring. 


\section{Literature Review}

Qualitative methods provide insight into how race occurs across place, complementing quantitative analyses of why shifts in race and place occur simultaneously (Bratter \& O'Connell, 2017; MacNamara \& Hilevych, 2015; O'Connell, Bratter, Casarez, 2020; Pickett et al. 2019). Rather than illustrating racial dispersion across place and time (Martin et al. 2017), qualitative research can illuminate how people understand racial categories and how categories of race are reproduced across place. Many demographers focus only on quantifiable variables, but other social scientists have more flexibility in terms of unpacking context and meaning (Obermeyer, 1997; Pollak \& Watkins, 1993). A tendency for academic structures to promote siloed work rather than interdisciplinary innovation has led to a divide between traditional demographic studies of race and studies informed by critical race theory. This study aims to bridge the divide between traditional, quantitative demographic studies of race and more critical studies of race, allowing an ethnographic examination to inform the way that quantitative demographic studies conceptualize the category of race. The tools of large-scale, quantitative demography cannot capture the nuances of race that are possible to glean in an in-depth ethnographic study, just as the tools of ethnography are not able to produce the broader analyses of a large-scale quantitative study; however, taken together, the insights of ethnographic studies can elucidate microprocesses of race and place that can then shape the way that we understand the category of race in spatial demography.

Scholars of race typically view race as a socially constructed category, rather than a fixed characteristic rooted in biology (Lopez, 1995; Omi \& Winant, 2014; Saperstein \& Penner, 2012; Smedley \& Smedley, 2005). Various scholars trace the creation of racial ideology to the colonization of the Americas, pointing to clear historical moments in which racial categories that so many now hold to be self-evident were in fact invented (Golash-Boza, 2019; Montagu, 1997; Quijano, 2000; Smedley, 2018). Scholarship reveals that definitions of race shift across place and over time (Davis, 2010; Saperstein \& Penner, 2012). However, despite the general consensus among race scholars that race is a social construct, empirical studies often treat race as a fixed category, even in disciplines where race is commonly understood to be socially constructed and malleable (Penner \& Saperstein, 2008; Zuberi, 2000).

Various quantitative demographers have undertaken the challenge of studying race as a flexible construct (Liebler \& Hou, 2020; Liebler et al. 2017; Saperstein \& Penner, 2012). Liebler et al. (2017) explore how racial self-identification shifts in the United States over time, looking particularly at the difference between the 2000 and 2010 census. The authors note that though many social scientists view race and ethnicity as social constructions, their research often does not reflect this by depicting race and ethnicity as unchanging (Liebler et al. 2017: 260). Liebler et al.'s (2017) data do not reveal why race and ethnicity responses sometimes change, merely that it does, in fact, occur. An ethnographic study such as this one paired with Liebler et al.'s (2017) findings could reveal how and why race and ethnicity shift over time.

In an analogous study, Liebler and Hou (2020) examine the stability of racial identification in Canada, finding that similar to the United States, "White" is 
the most stable response group. The shift in racial self-identification in Canada emphasizes that racial categories are socially constructed and malleable. Race is complex and difficult to capture in a closed-ended question, as in large surveys (Liebler \& Hou, 2020: 1). The Black response category was less stable in Canada and the UK than in the United States, which Liebler and Hou suggest could be attributed to the "differences in the history of migration, enslavement, segregation, resistance, and incorporation of Blacks into the broader society" (2020: 8). As this article will show, context with regards to migration, segregation, and the presence or absence of race riots plays an important role in shaping the ways in which race is constructed and maintained across different locales. Liebler and Hou write, "The social construction of race may be substantially different in countries with very different histories of colonization, White dominance, and public stories about race" (2020: 14). Liebler and Hou (2020) emphasize the socially constructed nature of race, the limitations of studying race using largescale quantitative data, and the importance of taking the complexity of race into account when conducting quantitative research that reduces race to a simple and supposedly fixed category (2020: 15). I suggest that qualitative studies of race can complement large-scale quantitative studies by illuminating some of the nuances and complexities of race that are difficult, if not impossible, to capture on a large scale.

Taking a different approach to studying race, Saperstein and Penner (2012) assert that race is reproduced through micro-level interactions, writing, "While not negating the importance of these macrolevel changes, our results suggest that racial divisions are also defined at a much more local level: in coffee shops and classrooms and around the dinner table, as Americans grapple-consciously and unconsciously_with how to define themselves and others" (Saperstein \& Penner, 2012: 710). This means that in theory, micro-level interactions can challenge the dominant racial order; however, Saperstein and Penner's findings suggest that these microlevel interactions typically reproduce the existing racial order, reinforcing racial disparities (2012: 710). In line with Saperstein and Penner's assertion that micro-level interactions shape race, this study uses micro-level data to illustrate the daily interactions through which race is constructed. This study reveals the tensions between race and ethnicity and how country of origin or status as a foreigner shapes one's placement within the racial hierarchy in two different locales.

Similar to calls for the field of demography to engage with feminist theory and gender as a social construction (Williams, 2010), I urge scholars to engage quantitative studies of race with critical race theory, following the lead of demographers such as Saperstein and Penner in looking at race as a socially constructed category. Moreover, intersectional approaches will be particularly beneficial. To engage the demography of race and place with scholarship on intersectionality allows for the deepening of understandings of how race functions in society. Too often, race and gender have been studied separately, without a profound understanding of how these categories are interlinked (Glenn, 1999). First developed by Kimberlé Crenshaw in 1991, the concept of intersectionality illuminates how different social identities, such as race, gender, and class, work together in concert to uniquely situate marginalized people in society (Collins \& Bilge, 2020; Crenshaw, 1991; McCall, 2005; 
Yuval-Davis, 2006). In "Mapping the Margins" (1991) Crenshaw develops a theory of intersectionality while examining the experiences of women of color in shelters, highlighting how race and gender make it so that women of color experience social oppression differently from men of color, and differently from White women. Pairing scholarship on race and demography with the experiences of Haitian women and the theory of intersectionality can reveal nuances about the role of race in society that would otherwise be difficult to see without bringing together this scholarship with this set of qualitative data.

\section{Historical Context of the Haitian Diaspora}

The first major wave of emigration from Haiti occurred in the 1960s and 1970s during the dictatorship of then-president Francois Duvalier (Basch, Glick Schiller, and Szanton Blanc, 2005). The political unrest and violence characteristic of his regime led many educated middle- and upper-class Haitians to flee, primarily to the United States and Canada, though some Haitians also moved to other locations in the Caribbean and Europe (Basch, Glick Schiller, and Szanton Blanc, 2005; Delachet-Guillon, 1996).

This paper focuses on the experiences of Haitian women in Boston and Montreal as two of many important sites within the Haitian diaspora. Many Haitians in this first wave of migration ended up in New York City, though Boston also became an important site where Haitians relocated. Today, Boston is home to the third largest Haitian population in the United States, following New York and Miami. The 2019 American Community Survey reports just over 68,800 people of Haitian ancestry in the Boston metropolitan area (Ruggles et al., 2020). Though a large and thriving Haitian community exists in Boston, very little research has been done on Haitians there compared to the amount of research on Haitians in places like New York and Miami (e.g. Brown \& Michel, 2010; Clerge, 2019; John, 2020; Mooney, 2009).

A strong Haitian diaspora in Montreal was established in the first wave of emigration from Haiti in the 1960s. Montreal's Haitian community was like Boston's in that they both consisted primarily of educated, middle- and upper-class Haitians ${ }^{1}$ fleeing political unrest and economic instability in Haiti (Jackson, 2011; Mills, 2013). This wave of migration coincided with Quebec's "Quiet Revolution," a time when Quebec actively sought out skilled laborers to support their economy (Mills, 2013; Pegram, 2005). Though European workers were preferred over Haitians in part because of anti-Black racism, middle- and upper-class Haitians were accepted as desirable immigrants due to their mastery of the French language. As of 2016, approximately 132,255 Haitians lived in Montreal (Statistics Canada 2016).

\footnotetext{
${ }^{1}$ I am referring to Haitians' class position in Haiti prior to migrating to the United States and Canada. The middle and upper classes make up only a small proportion of the overall Haitian population. As of 2012, the Haitian government estimated that $59 \%$ of the population lives below the poverty line (The World Bank 2020).
} 
Once vibrant Haitian communities were established in Boston and Montreal, initial immigrants then sent for family members and friends and helped them to settle in these metropolises as well (Basch, Schiller, Szanton Blanc 2005). The following sections present findings with regards to race in Boston and Montreal in 1960s and 1970s, race in contemporary Montreal, participants making cross-place comparisons, and examples of intersectionality. These findings reveal complexities and nuances of how Haitian women experience race across place and time.

\section{Methods}

This study draws on ethnographic methods, including participant observation and in-depth interviews with Haitian women, to examine the construction of race and ethnicity through paid labor. With fieldsites in Boston and Montreal, the data for this study were collected from 2011 to 2017. In total, I spent two three-month periods in Boston and six consecutive months in Montreal conducting fieldwork. The participant observation and interviews took place in a variety of locations, including in the homes and workplaces of participants. I also conducted participant observation at community events in the Haitian diaspora, such as conferences, book launches, folkloric dance classes, and festivals. I conducted and audiotaped 31 in-depth, semi-structured interviews, each between one and four hours in length, and compiled over 600 pages of typed fieldnotes based on participant observation. I recorded written fieldnotes by hand in a notebook during or immediately following observation and typed up a fully detailed record of my fieldnotes at the end of each day when I had returned home to my computer.

\subsection{Participants}

I identified one to two key informants in each fieldsite and proceeded to find participants for the study through snowball sampling, in which initial participants referred me to subsequent participants in their social networks. Each participant was a woman who was born in Haiti and later migrated to the United States or Canada. The women in this study were middle- or upper-class in Haiti prior to migrating, according to self-report, which shaped their social networks and the opportunities available to them post-migration.

\subsection{Self-reflexivity}

As a Haitian American woman, my identity enabled me to quickly build relationships and develop trust with my participants. The fact that my mother was of the middle class in Haiti also played an important role in facilitating my access, as class is crucially important in the organization of Haitian society. My participants were able to quickly determine my class by asking about my mother's family name and where in Haiti she was from. After providing this information and establishing myself as an honorary member of the Haitian middle class, participants often 
visibly relaxed as they recognized me as one of their own. I was perceived as both an insider because I am of Haitian descent and an outsider because I am second-generation Haitian, and in this way I was able to conduct research with an understudied segment of the population. The fact that I took it upon myself to learn Haitian Kreyòl as an adult and that I have studied Haitian folkloric dance for many years further cemented my status as an insider who could be trusted.

\subsection{Data Analysis}

My data analysis process draws heavily from grounded theory to identify key themes (Glaser \& Strauss, 1967; Lofland, 2006). I began to engage in the early stages of data analysis while in the field. The first stage of data analysis involved listening to interview recordings, reading through interview transcripts and fieldnotes, and reflecting on initial observations. I identified themes that emerged from this initial review of the data and began to loosely code the data according to these nascent themes. As I continued to code data, I wrote coding memos on some of the key themes and continued to conduct fieldwork, slightly narrowing my initially broad focus to ask questions specifically related to the themes revealed in the early stages of analysis.

Though the interviews were semi-structured, they covered a wide range of topics from growing up in Haiti, to migration, and life in their new homes. My fieldnotes were incredibly detailed, with notes about hair, skin tone, set up of rooms, and what was said, including interruptions. When coding my fieldnotes, I began very generally and once I refined my codes to key thematics, I focused my coding of the fieldnotes on references to those key themes: discrimination, inclusion, culture, and work.

The data for this article draw from a larger research project examining the themes outlined above. As the boundaries of race and ethnicity are often found through acts of exclusion at the margins, the findings for this article draw from ethnographic data that was initially coded as "discrimination." I also coded this data according to geographic location with codes for "Haiti," "Boston," "Montreal," and other Haitian diasporic locations. The final stage of data analysis involved reviewing all data under a specific code to look for trends, as well as for outlying cases.

\section{Findings}

This section presents findings from Haitian women's experiences in Boston and Montreal during the first wave of migration in the 1960s and 1970s to the early 2000s and 2010s. These findings illustrate the complex ways in which race and ethnicity are uniquely constructed in different places. This information can reveal to quantitative spatial demographers that when looking at numbers regarding race in multiple places, it is crucial to keep in mind that what it means to be Black in one place differs from what it means to be Black in another place. The lived 
experiences behind the numbers must shape our understandings of macro-level data on race.

\subsection{Boston}

When reflecting on their experiences in the 60 s and 70s, Haitian women in both Boston and Montreal found that their race as Black and their ethnicity as Haitian were tightly intertwined and, at times, seemingly at odds with each other. Josephine ${ }^{2}$ moved from Haiti to Boston with her family in 1975 when she was in early adolescence. She remembered feeling afraid and struggling to find her place within the racially charged setting of Boston in the 1970s. She explained the stress of stepping into a public school during desegregation and feeling caught between White and African American teenagers. Josephine outlined the complicated landscape of race and ethnicity, two important demographic categories, as related to place, in this case Boston:

I went to Hyde Park High. At the time, it was being desegregated, and it was during busing. We were bused to school, with police escort. We had riots every other day. You're in class one minute, next thing you know riot, boom, you're home. So you were not getting a proper education. So they resented us being at the school, and quite frankly we didn't want to be there...

But you get thrust into Boston in the middle of desegregation and it's racist and it's cold. The Black kids don't like you. The White kids don't like you. The Haitian kids who are somewhat hip don't want to associate with you because you've just come. You're a little Frenchie. You dress differently, you speak differently. Your manners are different. You're different. You're like a fish out of water. It was hard...

Well, I think the American kids-White kids didn't like you point blank because you were Black. The Black kids didn't like you because you spoke differently, you looked differently, you acted differently. And I'll have to tell you this. In junior high, it's the strangest thing, the White teachers, I think, probably perpetuated this because the Haitian kids were primarily very polite and very docile. I don't want to say subservient, that's not the right choice of word. But very-meek is not right. I think I know where I'm trying to go... Very respectful. This is how we were brought up. We say please, we say sir, we say ma'am. We do listen. It's a different culture, that's just how we were brought up. So the White teachers, somehow, treated the Haitian kids a little bit different.

-Josephine, Boston

Josephine explained that as Haitians, they were in a difficult position where they faced animosity from both White kids and other Black kids in school. Even though she was a Black student, she experienced race and discrimination very differently

\footnotetext{
${ }^{2}$ All names of participants are pseudonyms.
} 
from African American students. A bird's eye view of race in that moment in time might group all Black people together, and in some ways Black people were unified in their experience of anti-Black racism; however, Haitians also experienced discrimination from African Americans for being foreigners and at times received preferential treatment where White teachers expressed a preference for Haitian students over African American students. Josephine's experience reveals that divisions between racial and ethnic groups were established and reconstituted in daily life within public schools. Conflicts between racial and ethnic groups, as well as preferential treatment of Haitians over African Americans, shape the ways in which people make meaning of racial categories.

Nadège, a little older than Josephine, moved to Boston with her husband while eight months pregnant in 1968. When I asked her if she or anyone she knew was treated differently because they were Haitian, Nadège responded:

Uh, well. You know at that time the segregation was there. So Black people, they just look at you different way. But I never had anything happen to me since I came here, like people chasing me. Even though, when I went to school, I went to South Boston. The school was in South Boston...But you just stay in your area. You don't leave it. Because at that time it was, they had the busing...I remember I have a cousin of mine who went to Hyde Park [High]...she was going to high school...Police have to escort the bus to go to the school. So, but nothing ever happened to me. So, that was okay.

-Nadège, Boston

Nadège experienced the stressors of busing and desegregation secondhand as a parent and as an extended family member. From her persepctive, the major conflict in Boston at the time was along Black/White racial lines rather than between Haitians and Americans. However, this theme of tensions between Haitians and African Americans in schools extended to interviewees' description of race and ethnicity in workplace experiences. Later on in the interview when asked if she ever experienced preferential treatment for being Haitian, Nadège responded:

No, no. You know, after all, there, there, there was like, if you, like where I work and they know I'm Haitian, it's like, I don't know, they say, "You're not Black American." You know what I mean? "You come from somewhere else." So, I think, they give me more preference, you know, than them. But that's the only thing.

- Nadège, Boston

According to Nadège, this type of preferential treatment for Haitians over African Americans happened frequently in the workplace. Flore, a woman who migrated to Boston in the late 1950s with her husband, confirmed that employers often preferred Haitians to African Americans in the workplace, framing Haitians as "good" workers in contrast to the racist stereotype of African Americans being lazy or not working when at work. In her pride over the touted Haitian work ethic, Flore perhaps inadvertently reinforced the problematic notion that African Americans are not good 
workers. Flore's statement reveals an important schism within the Black community in Boston along ethnic lines. According to Flore:

Because Haitian people, there is something good in Haitians. When they come here, they work. They see Haitian people will have two, three jobs. When they go to do a job, they work.

Every Haitian who goes to hospital, they like them because they're very hard workers. I don't know if you heard that talk. But they are hard workers. They did like Haitians. Matter of fact, they said, if you say you're Black, they say, you're not Black, you're Haitian. But I don't know, you're not Black, you're Haitian. That's the way they used to put Haitian people. You are not Black.

-Flore, Boston

In Boston in the 1960s and 1970s, Haitian women's experiences of race and ethnicity were closely tied to African Americans. At times, Haitians were grouped with African Americans and experienced strong anti-Black racism. At other moments, Haitian women signaled to an uneasy tension between themselves and African Americans. Though both groups were Black, Haitians perceived animosity from African Americans, perhaps especially in educational settings. The women in this study explained that both teachers and employers gave Haitians preferential treatment over African Americans, fueling the tension between the two groups though they shared a common racial identity.

In addition to race, ethnicity, and status as a foreigner, class also plays an incredibly important role in the lives of Haitians in diaspora. Flore and her husband were one of the first Haitian families in Boston in the late 1950s. When I asked her if she knew many Haitians in the area now, she told me that she only knew a few. She explained:

Because seriously I didn't stay too much with Haitians. Because okay, you don't know maybe. There's different class of Haitian, you know what I mean. Like this is my friend, we always got good time together. I have a friend, she's not living far from me. I have limited my friends, because like there are Haitian people in those two houses. I don't know them. It's just, that's the way it is. Like I said before, I got friend or they're not in Boston, they are in the suburb, in Massachusetts... around Boston. But I don't have too many.

-Flore, Boston

In this passage Flore explained to me that she only mingles with Haitians of her own upper social class. She almost let that fact go without saying, but then it occurred to her that as a second-generation Haitian I might not understand how important social class is to Haitians in Haiti as well as in diaspora.

\subsection{Montreal}

Haitian women reported racism shaping their experiences in Montreal in the 1960s and $70 \mathrm{~s}$ up through the contemporary context as well. Rather than violence or overt 
hostility as Haitians in Boston sustained in the 60s and 70s, in Montreal, Haitian women recalled their interactions in that time were marked with confusion and standoffish behavior. Simone, a retired physician who moved from Haiti to Canada in the early 1960s, spoke of her experiences of race in the workplace as one of the few women and few Black doctors in Montreal in the 1960s and 1970s. When asked if she ever experienced racism in the workplace, Simone replied:

With the patients, never. But there's a nuance there: they need me. With the staff what struck me was when I finished my residency and became a full doctor. An important doctor, who turned out to be a wonderful man, arrived [in my department one day when the others had gone to lunch]. He had a [microscopy] slide in his hand [for me to examine]. He came into the office and said, "There's no one here." Oh, I came to realize that I was nobody here. He went to see the chief technician, an Italian man, who said, "Didn't you see the doctor in the office?" He thought the doctor he was looking for was a White man, so he didn't know if I was the housekeeper or what I was doing there. The Italian man brought him back and introduced me. He said, "Give her the slide. She will tell you what it is." Since that time, it has been the most complete respect. It is kind of subtle prejudices that come up with strangers... it is difficult to accept difference...

\section{-Simone, Montreal}

Contrary to instances of overt hostility and even violence in Boston at that time, Simone remembered being dismissed and not fully taken seriously in her role as a physician in this encounter. However, Simone insisted that it was only a mistake during her first meeting with this other doctor and that once he realized his mistake, he was nothing but respectful. The other doctor possibly mistaking Simone for a housekeeper speaks to how disconcerting it was for him to see a Black woman in the role of a physician, belying his assumptions about the role of Black women in the workplace. This quote lays bare the ways in which Simone experienced race, a crucial demographic category, in a particular place, Montreal. The differences between the ways that Haitian women experience race in Montreal and Boston illustrate how place plays an important role in shaping the category of race not so far as who identifies as Black, but in terms of what it means to be Black in daily interactions.

Guerda, a retired nurse in Montreal, recounted the history of the Haitian migration in Quebec alongside the misguided assumption that Montreal has always consisted of White French Quebecers. She remembered the mayor's office "welcoming" Blacks to Canada in the 1970s when Blacks had in fact been in Canada for generations at that point. Guerda explained:

Black anglophones have been around longer than we [Haitians] have. They are part of the Commonwealth. Their entry to Canada was assured. It was less complicated for them and it led to several generations of Black anglophone Canadians long before the arrival of Haitians in the 50s and 60s. And now the representative of the mayor says "Welcome to the country," and I say to myself, "This isn't possible!” Most Blacks here are anglophone. It was the 70s 
and there were Black people who had been there for one or two generations and they welcomed them! Something's not right.

-Guerda, Montreal

In the above passage, Guerda expressed frustration at the erasure of the existence of Blacks in Canada, and differentiated between the history of anglophone Blacks and Haitians in Canada. Unlike in the Boston context, Guerda did not signal that there was a tension between anglophone Blacks and Haitians in Montreal; instead, her upset over the way in which Black Canadians were "welcomed" to the country as though they had not already been a part of Canadian society for decades indicates a sort of solidarity between Guerda as a Black Haitian and anglophone Blacks in Canada, in contrast to the tense relationship between African Americans and Haitians many women reported during that same time in Boston. The difference in the relationship between native-born Blacks and Black Haitians in Montreal and Boston speaks to the ways in which the categories of race and ethnicity can only tell us so much without the deeper contextual knowledge of how these categories are forged and maintained in particular places. These ethnographic findings can add richness to how spatial demographers think about frequently used categories of race and ethnicity.

In discussing their experiences of race, the Haitian women in this study frequently talked about other intersecting aspects of their identities that impacted them simultaneously. They did not experience being only a Black person in Boston or Montreal, but they experienced being a Black person with ever-present gender, class, and national identities that shaped the ways in which they experienced race and racism. Guerda recounted the challenges of being a Black woman in Montreal in the 1970s:

The 70s were difficult for Black women...It's still difficult. My daughters who were raised here are more at home than me in my era...It's being a woman first, and being Black on top of that, you have two obstacles... We were expected to stay in our low-level jobs and not advance. There was this condescendence. I remember when I arrived at the hospital for my job and they all knew that I was the new hire, but no one would even look at me. I was the only Black person there. So I loudly said, "My name is Guerda. I am a part of your team now." A few years later, when they had come to trust me, they told me that they were not very happy that I had started working with them because they were not used to working with Black people. So that's the challenge. I had to teach my children to complete work properly so that people couldn't say that Black people don't know how to work. I asserted myself by doing my job well and keeping my identity... You must fight, but not be too aggressive or the message won't get through. It makes them use logic to evaluate me according to my values and my actions. The danger is there... I have small children. We try to train them so that they are sure enough in themselves not to be swayed or dismissed by the system. ${ }^{3}$

\footnotetext{
3 Translated from French by the author.
} 


\section{-Guerda, Montreal}

For Guerda, her experience as a woman was inextricable from her experience as a Black person in Montreal. The intersecting identities of being a Black woman shaped the way that Guerda and her daughters moved through the world and the way others interacted with them. Similarly, Suzette, a woman in her 50s with light brown skin and straightened, shoulder-length hair, described the compounded challenges faced as a Black, foreign woman in Montreal with regards to finding employment that matched her qualifications.

Fieldnotes excerpt:

Suzette explained that it is very difficult for a Black, foreign woman to find high-level work in Montreal. It is possible to find a nice job as a secretary, but not above that at the management level. She described this as 3 counts against her, enumerating the facets of her identity that limit her job opportunities on her fingers. When I asked if she faced discrimination because she is Haitian, she quickly corrected me saying that it was because of the color of her skin and the fact that she is a foreigner.

-Suzette, Montreal

Suzette confirmed what other Haitian women in both Montreal and Boston attested to, that they exist at the intersection of multiple aspects of their identities, making it impossible to understand their experience of race in isolation.

Most of the participants in Boston and Montreal left Haiti as part of the first wave of emigration in the 1960s and 70s; however, especially in Montreal, participants also included women who immigrated in the 2000s. Gina, a nurse in Montreal, was in her $30 \mathrm{~s}$ when I met her in 2017. She was of average height and build with medium brown skin and natural, black hair pulled back in a tight bun. Gina recounted her experiences with racism in the workplace as a nurse, and also in her schooling.

When I started in the workplace I was 19-20 years old and I experienced much more blatant racism, like nurses who did not want to take my report at the end of the shift because they said they did not understand my accent [even though when] I was in France...I was told that I spoke with a Quebec accent. But I understood that it was not because of my accent, but because of who I am... Outside of work this group of nurses were friends and when they invited each other to do things one of them asked if they weren't going to invite me too. The woman responded, "No, her color will dirty my spa."

I hadn't experienced this in primary or secondary school, but with adults. There were three of us Black nurses in the department and they said "We shouldn't put them together otherwise nothing will be done tonight." We said, "No, we won't change our team." By continuing to work I learned to hold my ground and there are things that don't happen anymore, but there are still things that are done in a sneaky way. The story of, "Oh, you're good. You're not like other Blacks," I hear it on a regular basis. What is terrible is that every 
time they think it's a compliment. It makes me laugh. Once I said, "Would it make you happy if I told you that you weren't like other White people? You would find it weird because you think other White people are decent, right? So what do you think that makes me feel? Because I like to be like other Blacks. I am proud to be Black. You insult me when you say that" ...

I experienced a lot of racism at all levels. Not necessarily being called a negro, but sneaky comments on a regular basis. But I have a strong personality. People cannot tell me things directly so they are careful. For example, "Oh, you Black people speak loudly." It's not true. We don't all speak loudly, just like Asians don't all speak in a low voice. It's not a [racial] characteristic.

A nurse came to see me after work and she told me, "Gina, I don't like Black people, but I like you." [I thought to myself,] ever since I came to Quebec I've been fucked over by your government, and yet I still don't understand White people. She looked at me while I searched for an answer because what she said was aggressive, but in her head, she paid me a compliment. ${ }^{4}$

\section{-Gina, Montreal}

Interestingly, Gina does not count the sorts of comments regarding Black people she encountered from teachers as racism because it was less overt than the types of comments made by her colleagues in the workplace. As noted in the passages above, Gina experienced a range of racial discrimination from subtle racially charged comments disguised as compliments to overt racial hostility in the form of her colleague suggesting that Gina was dirty because she was Black. Though seemingly less problematic on the surface, subtle racial statements continue to maintain racial divisions, setting Black people apart from, and inferior to, White French Canadians.

In an example of the importance of the intersection of race and class for Haitians in diaspora, Gina explained:

I had another situation at nursing school where we had vaccinations to do. A lot of Haitians live in Montreal Nord so they told me, "You go to Montreal Nord because you know this clientele better. You're Haitian." What do you mean, ma'am? Not all Haitians live in Montreal Nord. Another White Quebecer lived there all her life but the teacher insisted on transferring me there because I was Black. I went there and it was extremely poor. It did not correspond to my experience, whereas it corresponded to the experience of the White Quebecer. When it happened to me I did not understand. I was 18, but for the teacher it seemed automatic that we had the same experience. It was only years later that I realized these teachers were full of prejudices. ${ }^{5}$

-Gina, Montreal

\footnotetext{
4 Translated from French by the author.

5 Translated from French by the author.
} 
According to Gina, her teacher problematically grouped her with poor Haitian immigrants of Montreal Nord, assuming that since they were all Black and Haitian that Gina would have an innate understanding of the population. However, in this instance Gina knew nothing about Montreal Nord because although Black and Haitian, she was of a different social class and therefore separate from the residents of Montreal Nord, both geographically and in terms of experiences. By only connecting with Haitians of their own social class, Haitians of the middle and upper classes in Boston and Montreal maintained their social and cultural capital within their limited group, excluding lower-class Haitians from some of the benefits that they enjoy. By maintaining these closed networks, Haitians of means can share job and housing opportunities with each other, positioning themselves in American and Canadian society favorably in relation to other minorities, including other Blacks and even other Haitians.

With regards to subtle racial encounters, during my fieldwork in Montreal in 2016, three Haitian women, Suzette, Martine, and Karine, engaged in a conversation after a Haitian folkloric dance class one day regarding how people frequently ask them where they are from. The following is an excerpt from my fieldnotes documenting the conversation:

The conversation turned to how Suzette and Martine are very upset that people in Quebec frequently ask them where they are from. They hate that question and want to insist that they are from/live here, just like everyone else...Unlike Karine, Suzette and Martine perceive this question to be a form of discrimination, trying to fit people into boxes. Martine says that people are even asking her 8-year-old daughter where she is from, even though her daughter was born in Quebec and knows next to nothing about Haitian culture. Karine was shocked and dismayed to hear that this question is even directed at a small child. Martine heatedly stated that it's as though her daughter can never be fully Quebecois. She also said that when people ask her that question she always turns it right back on them and ask where they are from, even if they are blond and clearly French Canadian. Karine said that people are curious, and it's not their fault, they're just ignorant. Martine and Suzette agreed that there are a lot of ignorant people.

\section{-Montreal}

In Montreal, where there is not the same history of large numbers of African slaves, being Black has become closely tied with being a foreigner. Though not explictly stated in the conversation documented above, the implication is that French Canadians question Martine's daughter's nationality because her daughter is Black and therefore assumed to be foreign. Martine clearly frames White, blond people as presumed to be a part of Quebec, and expresses frustration that her daughter is denied that sense of belonging in the only place she has ever known simply because she is Black.

Following the theme of assumptions made regarding who belongs in Quebec with regards to race and ethnicity, Guerda emphatically denounced a video that was released in celebration of the founding of Montreal: 
Watch what happened yesterday. They released a video to celebrate the 375 th anniversary of Montreal with only White people...And in 2017, while 32\% of Montreal's population is from other places, when you make the video at least you should watch it before the release. How is it that the representative or the mayor or the person responsible for this video centered it on themselves! ${ }^{6}$

-Guerda, Montreal

In contemporary Montreal, Guerda and Martine signal that race is tightly tied to assumptions regarding who belongs in Quebec. In contrast, in the United States, Black people have long been understood to play a role in the nation, albeit a subjugated role. In Montreal, those in power create an erasure of Black people from the national landscape through actions such as the creation of the video about which Guerda spoke.

\subsection{Cross-place Comparison}

Many of the women interviewed had either lived in multiple sites in the Haitian diaspora, or at least had family in other locations. These connections to sites in other countries allowed them to compare how race plays out in different geographical locations. In addition to describing the racial climate in Montreal, Gladys drew comparisons between race in Montreal and race in the United States.

I think for us Blacks we are lucky in the sense that contrary to the United States we are not "ghetto," and I can see that when I go to see my family in the United States. There you have only two Whites but it's a predominantly Black neighborhood. Segregation is still there.

When talking about how she no longer knows people in Haiti, Gladys explained:

You have another view of the world. And you live in another reality. And I could see the difference even with the people in the States. When you talk to the people in the States they say, "You're different." And that is important because the segregation factor is not at work here.

-Gladys, Montreal

For Gladys, the history and continued reality of racial segregation in the United States plays a crucial role in how race plays out differently in the United States as compared to where she lives in Montreal. The ghettoization of Black space caused by intense segregation shaped the experiences of her Haitian family members in the United States. While Gladys and her family in Montreal certainly faced their fair share of racial discrimination, she differentiated her experiences of racial oppression from those of her family in the United States because she did not have the added factor of racial segregation in housing in Montreal.

6 Translated from French by the author. 
Fabienne initially moved from Haiti to Montreal, and later from Montreal to Boston. When asked if she had experienced racism in Boston as well as in Montreal, Fabienne replied:

Oh my god, yes! Well differently because I wasn't in school. My godmother lived in Hyde Park and this was the time where Black people were slowly moving into Hyde Park and there were still a lot of Irish people there who were resisting Black people moving in. Even on the street where we lived we had an Irish neighbor at night they would throw eggs at our door. Myself and my cousin who was around my age, my aunt's son, when we realized they were doing that they gave us our allowance money and we would set aside money to buy eggs and when they went to bed at night we would throw eggs.

One day I was in Clary Square in Hyde Park waiting for the bus and some young White men, shirtless, were in a car and calling me names and gestured that they were making a U-turn to come around. I was standing in front of a Papa Gino's ${ }^{7}$ and luckily people must have seen that and quickly came out and got me and brought me inside the restaurant.

I asked her if anything like that happened on the streets in Montreal and Fabienne replied:

No, never. I don't recall anyone ever calling me names. I didn't fear for my safety. It was different. For instance once I was in a bus and a Canadian woman very loudly I think I was standing and she was sitting down and she said in Canadian French, and I was just 14 years old and I was still slowly processing this whole racism thing and she said to me, "Oh, you. You are not ugly for a Black girl." But I had no clue what she was saying because I was raised to be complimentary I said very calmly, "Thank you, Madam. You are also not ugly for a White woman." It felt like a strange way to give a compliment but I figured that's how I'm supposed to return it.

-Fabienne, Boston

For Fabienne, she feared for her safety in Boston and was able to recall instances where she was in danger because of the high racial tensions in the city. In contrast, she described the racism that she experienced in Montreal as a backhanded compliment from a French Canadian woman. Others point to segregation in the United States as a crucial difference that shaped Haitians' experiences of race differently in the United States and in Quebec.

\footnotetext{
7 A pizza restaurant chain in Boston.
} 


\section{Discussion and Conclusion}

As scholars of race and demography tend to agree, race is socially constructed. I argue that the social construction of race is closely tied to place, and that the construction of race and the meaning of race is spatially-contingent (Bratter \& O’Connell, 2017; Pickett et al., 2019; O’Connell, Bratter, Casarez 2020). Using the example of Haitian women in diaspora, this article illustrates how race is constructed across these different localities, each in a different country. This qualitative approach complements quantitative spatial demography analyses of race and place by highlighting how race is shaped through daily interactions. This ethnographic study encourages consideration of the micro, daily interactions that shape the construction and maintenance of categories of race and ethnicity across place, providing insight into how these categories of analysis in spatial demography came to be and how they are constantly in flux and remade.

This article demonstrates the kind of knowledge about race and place that ethnographic studies can generate. The types of knowledge generated by this study are not at odds with quantitative demographic analyses of race and place, but rather encourage a rethinking of race as a dynamic category of analysis, in line with the ways that some quantitative demographers such as Penner, Saperstein, and Liebler reveal the socially constructed nature of race through their work. While many demographic studies concentrate on quantifiable categories of analysis, as an ethnographer, I focus on how people make meaning of those categories. Though the structures of academia do not necessarily actively encourage an intermingling of traditional demographic and ethnographic analyses of race, I argue that this type of collaboration can work to enhance demographic studies of race through a deeper understanding of how race is constructed and what racial categories mean to people in their daily lived experiences.

While maintaining Haitian identity, Haitian women also become raced in the context of their new homes. As the findings revealed, in the 1960s and 1970s, Haitian women migrants often found their racial identity at odds with their ethnicity and status as foreigners. Haitian women entered Boston amidst race riots and desegregation through busing; however, segregation in Boston persists to this day (Logan \& Stults, 2011). As Nadège stated, in order to stay safe in Boston at that time, "you just stay in your area. You don't leave it." While facing anti-Black racism, Haitians at times also experienced preferential treatment that placed them above African Americans in labor hierarchies and educational settings. This finding supports Mary Waters' (1999) discussion of intra-racial tensions between West Indians and African Americans in the United States.

Haitians in Montreal during this same time faced subtle racism compared to the overt and even violent racism taking place in Boston. Part of the reason for Haitians experiencing race so differently in Montreal can be attributed to the fact that Black anglophones have been largely rendered invisible in Quebec. Due to this erasure of Black presence, White Quebecois appeared startled to have Black people in their space upon the arrival of Haitian migrants. This finding elaborates on Liebler and Hou's (2020) observation of racial categories in Canada and the United States. The 
daily lived experiences of Haitian women in this study show that the historical context of place in Boston and Montreal shape their experiences of race.

In contemporary Montreal, subtle racism continues in schools and in the workplace (Labelle, 2004; Mahrouse, 2010). More recent Haitian migrants recounted stereotypes of Black people that are now articulated in ways that earlier migrants did not report. Race is shaped in each of the interactions described above, differentiating Black Haitian women from the White French Canadian majority in subtle but meaningful ways. Haitians in both Boston and Montreal experience xenophobia in addition to racism; however, for people in Montreal, an important distinction is that race is constructed in xenophobic terms of who belongs in Quebec.

Haitian women themselves provided a cross-place analysis of race in Quebec versus race in the United States based on their own experiences living and maintaining familial networks across place. According to the Haitian women participants in this study, segregation in the United States shapes the experience of race differently than that in Quebec. Also, for migrants in the first wave, the threat of racial violence that they experienced in Boston simply was not present in Montreal because of the broader racial contexts of Montreal and Boston at that time. As Liebler and Hou (2020) wrote, the experiences of Haitian women in Boston and Montreal differed in part because these places had different "public stories about race" (14).

Race and gender are not additive categories that can be easily quantified (Crenshaw, 1991). The complexities of these intersecting categories necessitate the need for qualitative studies to highlight how these categories work simultaneously in people's daily lives in ways that large-scale quantitative studies may not be able to capture by nature of their design. The solution is not merely to tweak the design of large-scale quantitative studies, but rather to engage that research with ethnographic research on race and gender, allowing ethnographic research to inform the way that large-scale, quantitative demographers understand their categories of analysis and ultimately make sense of their findings. Race is constructed and experienced alongside other social identities such as gender and class (Collins \& Bilge, 2020; Crenshaw, 1991; McCall, 2005; Yuval-Davis, 2006). It is not possible to fully isolate race; it is important to keep this in mind when conducting both quantitative and qualitative research on race. All social identities are constructed dependent on the local context and are therefore place-dependent. There are certainly similarities in these social categories across place, but it is important not to essentialize or collapse categories for the simplicity of research design.

One alternative to oversimplifying categories of race may be to use geographically weighed regression and spatial regimes to account for variations in the construction and experiences of race across place (e.g. Pickett et al. 2019). Curtis and O'Connell (2017) take this approach to reveal how the historical context of slavery shapes contemporary relationships between Black populations and racial inequality in the United States. While looking at historical events is an important approach to understanding the variation in race and racial inequality across space (e.g. Bratter \& O'Connell, 2017), this study suggests that engaging with ethnographic data is another way for spatial demographers to shed light on variations of race across geographical locations. This study reveals the necessity of avoiding the oversimplification of categories of race because race is so locally constructed and experienced 
differently across place. Large-scale, quantitative spatial demography studies can use the findings of this study to unpack meta-level data on race and place by questioning the use of measures that depict race as a set of static categories with singular meanings. In cases where it is not possible to adapt research design to account for the malleable nature of categories of race, scholars can look to this study to understand the possible limitations of research designs when making sense of findings to bypass the pitfall of presenting findings regarding race and space in a way that reaffirms outdated conceptions of racial categories as static or monolithic.

Since this study looks specifically at the experiences of Haitian migrants and cannot be generalized to the experiences of all Blacks in the United States and Quebec, future studies may investigate similarities and differences in how race is constructed across place in the lives of other racial and ethnic groups to continue to create a fuller picture of how and why race manifests differently across place. Both ethnographic and large-scale quantitative studies in conversation with each other are needed to deepen our understandings of race and place.

\section{Declarations}

Conflict of interest The author states that there is no conflict of interest.

Open Access This article is licensed under a Creative Commons Attribution 4.0 International License, which permits use, sharing, adaptation, distribution and reproduction in any medium or format, as long as you give appropriate credit to the original author(s) and the source, provide a link to the Creative Commons licence, and indicate if changes were made. The images or other third party material in this article are included in the article's Creative Commons licence, unless indicated otherwise in a credit line to the material. If material is not included in the article's Creative Commons licence and your intended use is not permitted by statutory regulation or exceeds the permitted use, you will need to obtain permission directly from the copyright holder. To view a copy of this licence, visit http://creativecommons.org/licen ses/by/4.0/.

\section{References}

Basch, L. G., Schiller, N. G., \& Szanton Blanc, C. (2005). Nations unbound: Transnational projects, postcolonial predicaments, and deterritorialized nation-states. Gordon and Breach.

Bratter, J. L., \& O'Connell, H. A. (2017). Multiracial identities, single race history: Contemporary consequences of historical race and marriage laws for racial classification. Social Science Research, 68, $102-116$.

Brown, K. M., \& Michel, C. (2010). Mama Lola: A vodou priestess in Brooklyn (Vol. 4). University of California Press.

Carney, N. (2017). Multi-sited ethnography: Opportunities for the study of race. Sociology Compass, 11(9).

Clerge, O. (2019). The new noir: Race, identity, and diaspora in Black suburbia. University of California Press.

Collins, P. H., \& Bilge, S. (2020). Intersectionality. John Wiley \& Sons.

Crenshaw, K. (1991). Mapping the margins: Identity politics, intersectionality, and violence against women. Stanford Law Review, 43(6), 1241-1299.

Curtis, K. J., \& O'Connell, H. A. (2017). Historical racial contexts and contemporary spatial differences in racial inequality. Spatial Demography, 5(2), 73-97.

Davis, F. J. (2010). Who is black?: One nation's definition. Penn State Press.

Delachet-Guillon, C. (1996). La communauté haïtienne en Ile-de-France. Editions L'Harmattan. 
Falzon, M.-A. (2016). Multi-sited ethnography: Theory, praxis and locality in contemporary research. Routledge.

Glaser, B. G., \& Strauss, A. L. (1967). The discovery of grounded theory: Strategies for qualitative research. Aldine Pub. Co.

Glenn, E. N. (1999). The social construction and institutionalization of gender and race. Revisioning Gender, 3-43.

Golash-Boza, T. M. (2019). Race \& racisms: A critical approach. Oxford University Press.

Hannerz, U. (2003). Being there... And there... And there! Reflections on multi-site ethnography. Ethnography, 4(2), 201-216.

Jackson, Regine O. (Ed.). (2011). Geographies of the Haitian diaspora. Routeledge.

John, M. (2020). Haitian and Cuban immigrants in Miami, Florida: Are they more similar than they are different? African and Black Diaspora: an International Journal, 13(3), 314-329.

Labelle, M. (2004). The language of 'race', identity options and 'Belonging' in the Quebec context. Social Inequalities in Comparative Perspective, 39-65.

Liebler, C. A., \& Hou, F. (2020). Churning races in Canada: Visible minority response change between 2006 and 2011. Social Science Research, 86, 102388.

Liebler, C. A., Porter, S. R., Fernandez, L. E., Noon, J. M., \& Ennis, S. R. (2017). America's churning races: Race and ethnicity response changes between census 2000 and the 2010 census. Demography, 54(1), $259-284$.

Lofland, J. (2006). Analyzing social settings: A guide to qualitative observation and analysis (4th ed.). Wadsworth/Thomson Learning.

Logan, J. R., \& Stults, B. J. (2011). The persistence of segregation in the metropolis: New findings from the 2010 census. US2010 Project.

Lopez, I. F. H. (1995). The social construction of race. Critical Race Theory: The Cutting Edge, 191-203.

MacNamara, T., \& Hilevych, Y. (2015). Living in the demos: Qualitative approaches to demographic questions. The History of the Family, 20(1), 1-8.

Mahrouse, G. (2010). 'Reasonable accommodation'in Québec: The limits of participation and dialogue. Race \& Class, 52(1), 85-96.

Marcus, G. E. (1995). Ethnography in/of the world system: The emergence of multi-sited ethnography. Annual Review of Anthropology, 95-117.

Martin, M. J., Matthews, S. A., \& Lee, B. A. (2017). The spatial diffusion of racial and ethnic diversity across US counties. Spatial Demography, 5(3), 145-169.

McCall, L. (2005). The complexity of intersectionality. Signs: Journal of Women in Culture and Society, 30(3), 1771-1800.

Mills, S. (2013). Quebec, Haiti, and the deportation crisis of 1974. The Canadian Historical Review, 94(3), $405-435$.

Montagu, A. \& others. (1997). Man's most dangerous myth: The fallacy of race. Rowman \& Littlefield.

Mooney, M. (2009). Faith makes us live: Surviving and thriving in the Haitian diaspora. Univ of California Press.

O'Connell, H. A., Bratter, J. L., \& Casarez, R. S. (2020). One drop on the move: Historical legal context, racial classification, and migration. Ethnic and Racial Studies, 1-20,. https://doi.org/10.1080/01419870. 2020.1761554

Obermeyer, C. M. (1997). Qualitative methods: A key to a better understanding of demographic behavior? Population and Development Review, 813-818.

Omi, M., \& Winant, H. (2014). Racial formation in the United States. Routledge.

Pegram, S. (2005). Being Ourselves: Immigrant culture and self-identification among young Haitians in Montréal. Ethnic Studies Review, 28, 1-20.

Penner, A. M., \& Saperstein, A. (2008). How social status shapes race. Proceedings of the National Academy of Sciences, 105(50), 19628-19630.

Pickett, R. E., Saperstein, A., \& Penner, A. M. (2019). Placing racial classification in context. Socius, 5, 2378023119851016.

Pollak, R. A., \& Watkins, S. C. (1993). Cultural and economic approaches to fertility: Proper marriage or mesalliance? Population and Development Review, 467-496.

Haiti: Country Profile. (2020). The World Bank. https://data.worldbank.org/country/haiti?view=chart

Quijano, A. (2000). Coloniality of power and Eurocentrism in Latin America. International Sociology, 15(2), 215-232.

Roth, W. D. (2012). Race migrations: Latinos and the cultural transformation of race: Vol. null (null, Ed.). 
Ruggles, S., Flood, S., Goeken, R., Grover, J., Meyer, E., Pacas, J., \& Sobek, M. (2020). IPUMS USA: Version 10.0 . IPUMS. https://doi.org/10.18128/D010.V10.0

Saperstein, A., \& Penner, A. M. (2012). Racial fluidity and inequality in the United States. American Journal of Sociology, 118(3), 676-727.

Smedley, A. (2018). Race in North America: Origin and evolution of a worldview. Routledge.

Smedley, A., \& Smedley, B. D. (2005). Race as biology is fiction, racism as a social problem is real: Anthropological and historical perspectives on the social construction of race. American Psychologist, 60(1), 16.

Waters, M. C. (1999). Black identities: West Indian immigrant dreams and American realities. Harvard University Press.

Williams, J. R. (2010). Doing feminist-demography. International Journal of Social Research Methodology, 13(3), 197-210.

Yuval-Davis, N. (2006). Intersectionality and feminist politics. European Journal of Women's Studies, 13(3), 193-209.

Zuberi, T. (2000). Deracializing social statistics: Problems in the quantification of race. The Annals of the American Academy of Political and Social Science, 568(1), 172-185.

Publisher's Note Springer Nature remains neutral with regard to jurisdictional claims in published maps and institutional affiliations. 